\title{
XXXIII. On the nitroprussides, a new class of salts
}

\author{
Dr. Lyon Playfair F.R.S. F.C.S.
}

To cite this article: Dr. Lyon Playfair F.R.S. F.C.S. (1850) XXXIII. On the nitroprussides, a new class of salts, Philosophical Magazine Series 3, 36:243, 271-283, DOI: 10.1080/14786445008646474

To link to this article: http://dx.doi.org/10.1080/14786445008646474

曲 Published online: 30 Apr 2009.

Submit your article to this journal

Џ Article views: 2

Q View related articles ¿ 
When over a place about 37 miles from the first-mentioned place, its distance from the earth was 42 miles.

When over a place about 80 miles from the first-mentioned place, its distance from the earth was 25 miles.

When over a place about 90 miles from the first-mentioned place, its distance from the earth was 23 miles.

When over a place about 110 miles from the first-mentioned place, its distunce from the earth was 19 miles, when it exploded.

The curve described by the meteor was that of the parabola, as will be seen by laying the above numbers, or their complements, to 84 miles, upon a line of abscissa.

After the explosion, the luminous bodies were seen till they were within 10 miles of the earth. The report accompanying the explosion was so great, that I am inclined to believe that the substance of the meteor was of a firm texture, broken into many pieces by the extraordinary expansion of an elastic fluid; if so, its particles would fly off in all directions; some would describe parabolic curves, as mentioned by the Rev. C. J. Goodhart; some would continue to move with accelerated force in the same direction, and some would fall vertically. It seems probable that some parts of this body may have reached the ground within a few miles round Biggleswade. It seems certain that this meteor must have come from the regions of space far beyond the influence of our vapours ; and this fact, together with its extreme velocity, and the intensity of the light, are circumstances more conformable to a solid than to a gaseous substance.

[The original accounts will be preserved in the Archives of the Royal Observatory, Greenwich.]

XXXIII. On the Nitroprussides, a Nerw Class of Salts. By Dr. Lyon Prayfair, F.R.S., F.C.S.

[Continued from p. 221.]

Section 11I.-Changes experienced by certain Nitroprussides when their solutions are heated or kept.

18. QEVERAL of the nitroprussides, especially nitroprussic $\$$ acid, nitroprussides of ammonium, barium and calcium, deposit either prussian blue or oxide of iron when their solutions are heated or are kept for some time. The residual liquid, after evaporation, yields crystals of the same shape and exactly of the same properties as before. Analysis however 
shows that some change has resulted in their composition, for the iron or electro-negalive metal is now in greater than atomic proportion to the electro-positive metal. The proportion of carbon is also somewhat different. Still the difference in composition is not very considerable, although decidedly marked; it is not however sufficient to cause any obvious alteration in their general properties. In fact there is an attached impurity, probably a cyanide of iron, which cannot now be removed by crystallization, precipitation, digestion with nitric acid, or any of the ordinary means of purification. This impurity, if it be one, remains so obstinately attached that all methods of purification have quite failed to remove it. This circumstance, before it was understood, had thrown the greatest difficulties in the way of the inquiry, and protracted it to a most tedious lengtb by preventing the attainment of accordant results. It is to prevent the like inconvenience to those who repeat these experiments that this section of the paper is specially devoted. Attention has previously been drawn to the fact, that the nitroprussides form chemical compounds with the cyanides of iron. This seems to be a case of the same kind, but of more ultimate union. The impurity or chemically attached cyanide in this case appears to be $\mathrm{FeCy}^{2}$, or perhaps $\mathrm{FeCy}+\mathrm{HCy}$, judging from analysis only, for its separation has not been accomplished. The proportion in which it is present is very small, generally only $2\left(\mathrm{FeCy}^{2}\right)$ to 7 equivs. of a nitroprusside, or if it be a chemical compound, $7\left(\mathrm{Fe}^{5} \mathrm{Cy}^{12}\right.$ 3NO +5R) $+\mathrm{Fe}^{2} \mathrm{Cy}^{4}$. Still as the crystalline form and all the properties of the nitroprussides remain unchanged, we can scarcely view its presence in any other light than as an impurity. Several of the nitroprussides, viz. nitroprussic acid and the nitroprussides of ammonium and calcium, have not yet been obtained free from this impurity, and are therefore described in this section.

\section{Nitroprussic Acid.}

19. The mode of preparation of this acid has been already described at page 209 . It is however most readily prepared from nitroprusside of silver by adding to it as much hydrochloric acid as suffices to form chloride of silver with the silver in the salt. The dark red solution thus obtained soon evolves hydrocyanic acid, even in the cold, and after a time prusside of potassium indicates the presence of iron in solution. If the solution be heated, it deposits abundance of a brown precipitate resembling oxide of iron. When the latter is separated by filtration, and the solution is evaporated in vacuo over sul- 
phuric acid, crystals are formed and may be separated; they must be dried over sulphuric acid, as they are exceedingly deliquescent. These crystals belong to the oblique system, but on account of their excessive tendency to deliquesce, it is difficult to measure their angles with accordant results. The angles between normals to the only faces which gave results to be depended on, are stated by Prof. Miller to be as follows:-
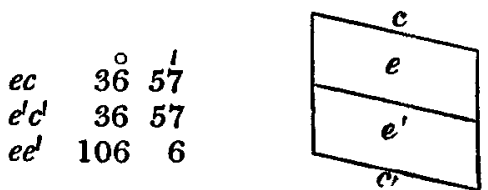

It will be seen that the equality of the angles $e c$ and $e^{t} c^{t}$ is a tolerably certain indication that the crystals belong to the oblique system.

The acid made by the action of hydrochloric acid on nitroprusside of siver, and evaporated over sulphuric acid in the cold, crystallized (light being excluded) without the deposition of oxide of iron, but the smell of hydrocyanic acid, accompanied by a peculiar pungent smell, was strongly perceptible. Analysis shows that these crystals are the same as those obtained from a boiled solution.

Properties of the Crystallized Acid.-The crystallized acid is of a dark red colour, and has a very acid reaction, the crystals being generally flattened and of tolerable size. They are quite as deliquescent as chloride of calcium. They dissolve to a large extent in water, and are also soluble in alcohol and in æether. They may be dried in the water-bath without change, but their aqueous solution cannot be boiled without decomposition.

The following analyses were made on crystals obtained from a boiled solution, and were dried at $212^{\circ}$. The acid was that made by the action of hydrochloric acid on the silver salt. Nos. I. Il. and III. were preparations made at distinct times.

The iron was determined by calcination and by treating the residual oxide with nitrate of ammonia.

I. $2 \cdot 34.5 \mathrm{grs}$. gave $0 \cdot 800 \mathrm{gr}$. peroxide of iron.

II. 3.915 grs. gave $1.325 \mathrm{gr}$. peroxide of iron.

III. 3.580 grs. gave 1.220 gr. peroxide of iron.

The combustions were made in the usual way.

I. 7.720 grs. gave 7.005 grs. $\mathrm{CO}^{2}$ and $1.175 \mathrm{gr}$. HO.

II. 10.810 grs. gave $9 \cdot 880$ grs. $\mathrm{CO}^{2}$ and $1.665 \mathrm{gr}$. HO.

III. 4.385 grs. gave $3.980 \mathrm{grs}$. $\mathrm{CO}^{2}$ and $0.700 \mathrm{gr}$. HO.

An estimation of nitrogen by Bunsen's method gave the following result:- 


$\begin{array}{lllll} & \text { Obs. vol. } & \begin{array}{l}\text { Barom. } \\ \text { inches. }\end{array} & \text { Therm. } & \text { Col. Merc. } \\ \text { Vol. of mixed gases (moist) } & 89 \cdot 5 & 29 \cdot 994 & 7 \cdot 0 \text { C. } & 152 \cdot 7 \\ \text { Vol. after absorption (dry) } & 37 \cdot 4 & 30 \cdot 015 & 9 \cdot 2 \text { C. } & 205 \cdot 2\end{array}$

Corrected vol. of mixed gases . . . 52.995

After absorption of carbonic acid . . 20.570

Nitrogen . . . $\overline{32 \cdot 425}$

Hence the proportion of nitrogen to carbonic acid is $1: 1 \cdot 576$.

\begin{tabular}{|c|c|c|c|c|c|c|}
\hline & I. & II. & III. & & & Calculated. \\
\hline Iron & . $23 \cdot 88$ & $23 \cdot 69$ & $23 \cdot 85$ & 5 & 140 & $24 \cdot 26$ \\
\hline Carbon & $24 \cdot 74$ & $24 \cdot 92$ & $24 \cdot 75$ & 24 & 144 & $24 \cdot 95$ \\
\hline Hydrogen & $1 \cdot 69$ & $1 \cdot 71$ & $1 \cdot 77$ & 11 & 11 & $1 \cdot 90$ \\
\hline Nitrogen & $36 \cdot 73$ & $36 \cdot 73$ & $36 \cdot 73$ & 15 & 210 & $36 \cdot 39$ \\
\hline Oxygen & $12 \cdot 96$ & $12 \cdot 95$ & $12 \cdot 90$ & 9 & 72 & $12 \cdot 50$ \\
\hline & $100 \cdot 00$ & 00 & 0.00 & & 577 & $100 \cdot 00$ \\
\hline
\end{tabular}

The calculated result, especially as regards the hydrogen, is not sufficiently close to be the true expression of the analysis, but it is here given to show how far the acid differs from pure nitroprussic acid. It is indeed probable that the acid dried at $212^{\circ}$ only contains 10 equivs. of water.

The acid is so remarkably deliquescent that it is very difficult to ascertain how much the crystals lose in the water-bath. The following analysis of the salt dried in vacuo over sulphuric acid shows a higher state of hydration. The sample analysed had never been heated, even in solution, so that it evaporated without the deposition of oxide of iron. Still the nxide was detected in the mother-liquor by ferrocyanide of potassium.

I. $3 \cdot 225$ grs. gave $1 \cdot 010 \mathrm{gr}$. peroxide of iron.

II. $3.235 \mathrm{grs}$. gave $1.020 \mathrm{gr}$. peroxide of iron. water.

I. 5.830 grs. gave 5.020 grs. carbonic acid and $1.09 \mathrm{gr}$.

II. 8.225 grs. gave 7.060 grs. carbonic acid and $1.51 \mathrm{gr}$. water.

\begin{tabular}{|c|c|c|c|}
\hline & $\begin{array}{l}1 . \\
21 \cdot 92\end{array}$ & $\begin{array}{l}11 . \\
22 \cdot 07\end{array}$ & $\begin{array}{l}\text { Mean. } \\
91 \cdot 99\end{array}$ \\
\hline Carbon & $23 \cdot 48$ & $23 \cdot 32$ & $23 \cdot 40$ \\
\hline Hydrogen & $2 \cdot 07$ & $2 \cdot 03$ & $2 \cdot 05$ \\
\hline $\begin{array}{l}\text { Nitrogen } \\
\text { Oxygen }\end{array}$ & $-52 \cdot 53$ & $52 \cdot 58$ & 52.56 \\
\hline & $100 \cdot 00$ & $100 \cdot 00$ & 00 \\
\hline
\end{tabular}

A silver salt made from the well-crystallized acid showed that the iron was in excess, and that the carbon was in the usual proportion (see pp. 280, 281). The analyses of these silver salts are given further on, in order to avoid repetition. 
The discussion as to the constitution of the acid is also deferred to that place.

Nitroprusside of Ammonium.

20. When ammonia is added to an excess of nitroprusside of iron the latter is decomposed, oxide of iron being precipitated, but during the action nitrogen gas is evolved. If the red-coloured solution caused by filtration be evaporated in the air-pump, a difficultly crystallizable salt is obtained, which very readily decomposes, turning blue in the water-bath, and even when dried over sulphuric acid in vacuo. This salt is probably the true nitroprusside of ammonium, but it has not been obtained pure for analysis. If a solution of this salt be heated, prussian blue is deposited, and the filtered dark-red liquid, being evaporated by a gentle heat, now crystallizes in a warm place very readily, and in fine large red crystals, which are so dark as to be almost of a black colour. These have been measured by Prof. Miller; they are prismatic, but the angles given are only approximative, the faces of the crystal examined being imperfect.

Symbols: $-c 001, m 110, u 011$.

Angles between normals to the faces:-

$$
\begin{array}{lrr}
m c & 90 & 0 \\
m m^{\prime} & 88 & 4 \\
u c & 55 & 3 \\
u u^{\prime} & 110 & 6
\end{array}
$$

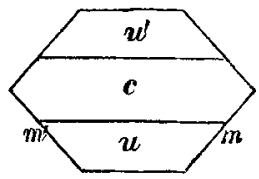

They are twin crystals, the twin faces being $m$.

This salt is very soluble in water, from which it is not precipitated by alcohol. It is very slightly deliquescent. The salt dried in air loses water in the water-bath.

18.648 grs. lost at $212^{\circ} 2.928$ grs., or 15.701 per cent. $10.915 \mathrm{grs}$. lost at $212^{\circ} 1.800 \mathrm{gr}$., or 16.491 per cent. 11.502 grs. lost at $212^{\circ} 1.948 \mathrm{gr}$., or 16.936 per cent. 45.400 grs. lost at $212^{\circ} 6.850$ grs., or 15.088 per cent.

$$
16 \cdot 054
$$

The iron was determined by calcination.

I. 10.905 grs. gave 9.455 grs. peroxide of iron.

II. 12.954 grs. gave $4.070 \mathrm{grs}$. peroxide of iron.

The combustions made with chromate of lead gave the following results :-

I. 9.822 grs. gave 2.903 grs. $\mathrm{HO}$ and 8.251 grs. $\mathrm{CO}^{2}$. II. $12 \cdot 765$ grs. gave 3.682 grs. $\mathrm{HO}$ and 10.494 grs. CO 2 III. 7.215 grs. gave $2 \cdot 010$ grs. $\mathrm{HO}$ and 6.020 grs. $\mathrm{CO}^{2}$. 

thod.

The nitrogen was determined by Dumas' quantitative me-

I. $4 \cdot 4.94$ grs. salt gave 112 C.C. gas, the therm. being $47^{\circ} \frac{1}{2}$ Fahr., barom. $29 \cdot 844$ in.

III. 3.372 grs. salt gave 83 C.C. gas, the therm. being $50^{\circ}$ Fahr., barom. $29 \cdot 550$ in.

This, calculated on $22 \cdot 7$ per cent. carbon, gives 43.619 per cent. nitrogen.

Again, $\mathbf{8} \cdot 747$ grs. salt distilled with a weak solution of soda, gave a distillate which, collected in hydrochloric acid, yielded 15.021 grs. platinum salt.

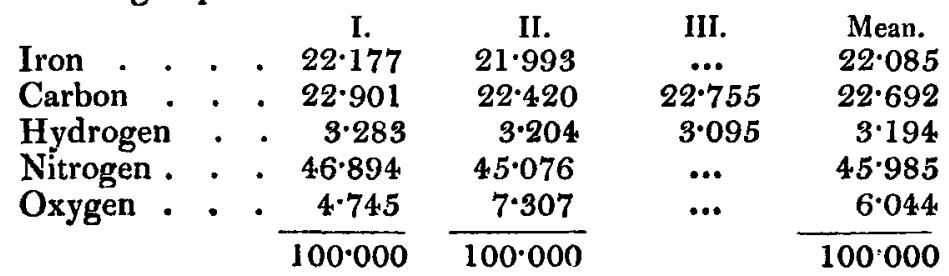

The ammonium per cent. from the amount of platinum salt is 13.872 .

It is obvious that there is little hydrogen as water, for the greatest part is required to make up the ammonium (13.872 per cent. requires 3.08 hydrogen). Reserving, as in the other cases, the discussion as to the cause of difference between this salt and the prue nitroprusside, it will be convenient to give the calculation for nitroprusside of ammonium, of which the formula would be $\mathrm{Fe}^{5} \mathrm{Cy}^{12} 3 \mathrm{NO}, 5 \mathrm{NH}^{4}+2 \mathrm{HO}$.

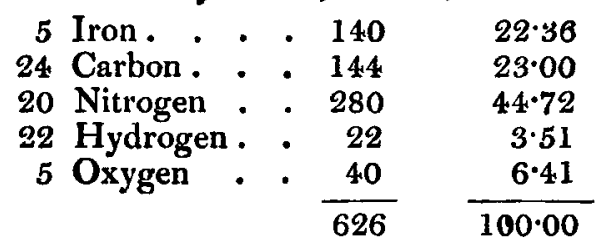

The hydrogen, but not the other constituents, would agree better with the above formula minus 2 equivs. of water; the hydrogen by the latter would be 3.28 per cent.

\section{Nitroprusside of Calcium.}

21. To prepare this salt, nitroprusside of iron or of copper is decomposed by milk of lime, the nitroprusside being kept in decided excess. A dark red solution is obtained, which on evaporation, even at a gentle heat, deposits prussian blue. When sufficiently concentrated the solution yields crystals of a dark red colour, and of considerable lustre. The crystals 
helong to the oblique system. They have been approximatively measured by Prof. Miller.

Symbols:- $a 100, c 001, m 110$; there are besides one or two faces in the zone $c m c$, the symbols of which have not been found.

Cleavage $a$ very perfect.

Angles between normals to faces approximately :-

$$
\begin{array}{lll}
a c & 8 \stackrel{\circ}{0} \\
m a & 70 & 0 \\
m m^{\prime} & 40 & 0
\end{array}
$$

The values of $c u$ were extremely discordant. In the best crystals, the angle between normals to $\mathrm{cu}$ was found to be $71^{\circ} 41^{\prime}$.

Nitroprusside of calcium is very soluble in water, and in its behaviour to reagents is exactly the same as the soluble nitroprussides already described. By the mean of two experiments the crystallized salt lost $17 \cdot 85$ per cent. of water in the water-bath at $212^{\circ}$.

The salt was analysed by fusion with nitrate of ammonia, the iron and lime being determined in the usual way.

13.29 grs. gave 4.004 grs. peroxide of iron and 4.698 grs. carbonate of lime.

8.33 grs. burned with chromate of lead gave 6.56 grs. carbonic acid and 0.82 water.

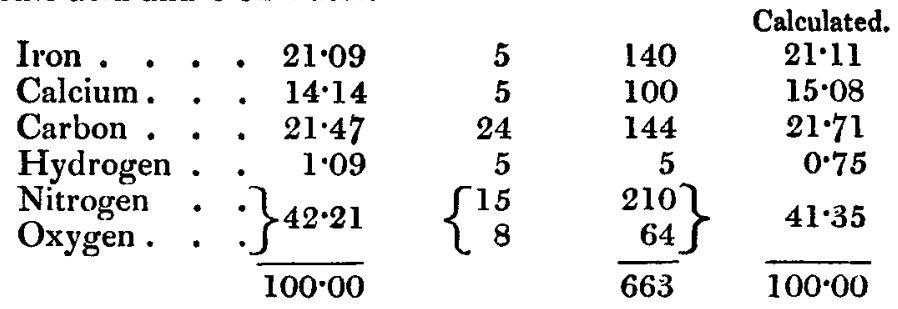

It will be seen that this salt belongs to the class which has dissolved some of the cyanide of iron resulting from its partial decomposition, and that therefore the electro-positive metal is in too small quantity. Allowing for this impurity, which cannot be removed, it is probable that the pure nitroprusside of calcium has the formula $\mathrm{Fe}^{5} \mathrm{Cy}^{12} 3 \mathrm{NO}, \mathrm{Ca}^{5}+5 \mathrm{HO}$. The loss of water in the water-bath corresponds to 15 equivs., which ought to have given the loss as 17 per cent. In one experiment it lost $17^{\circ} \cdot 4$, per cent., in another $18 \cdot 26$. We may conclude that the formula of the crystallized salt is $\mathrm{Fe}^{5} \mathrm{Cy}^{12} 3 \mathrm{NO}$, $\mathrm{Ca}^{5}+20 \mathrm{HO}$. 


\section{Altered Nitroprusside of Barium.}

22. When a solution of nitroprusside of barium is boiled, it deposits a brown precipitate containing both iron and barium*. The solution now crystallizes either in pyramidal or in prismatic crystals, that is, in the first state when crystallized slowly, in the second when deposited quickly from a hot solution. It is now found that the salt is inconstant in composition, different preparations giving very discordant results. The salt is however peculiarly difficult to dry, having to be kept in the water-bath for days before it ceases to lose weight; it abstracts water when dried most speedily from the atmosphere.

It is found that the carbon is increased in a marked degree. The following two specimens were made at different times and analysed. Analyses I. and II. were made on the same specimen, but crystallized over again for analysis II. No. III. is on a totally different specimen.

I. 14.40 grs. gave 8.62 grs. $\mathrm{BaO}, \mathrm{SO}^{3}$ and $3 \cdot 12$ grs. $\mathrm{Fe}^{2} \mathrm{O}^{3}$. II. 15.90 grs. gave $10^{1} 17$ grs, $\mathrm{BaO}, \mathrm{SO}^{3}$ and $3.68 \mathrm{grs}$. $\mathrm{Fe}^{2} \mathrm{O}^{3}$. III. $14 \cdot 135$ grs. gave $8.47 \mathrm{grs}$. $\mathrm{BaO}, \mathrm{SO}^{3}$ and 3.06 grs. $\mathrm{Fe}^{2} \mathrm{O}^{3}$.

The combustions were made with chromate of lead.

I. $11 \cdot 735$ grs. gave $7 \cdot 730 \mathrm{grs}$. $\mathrm{CO}^{2}$ and $1.390 \mathrm{gr}$. HO. II. $10 \cdot 610$ grs. gave $7 \cdot 145$ grs. $\mathrm{CO}^{2}$ and $0 \cdot 700 \mathrm{gr}$. $\mathrm{HO}$. III. 14.045 grs. gave $8.800 \mathrm{grs}$. $\mathrm{CO}^{2}$ and $1.900 \mathrm{gr}$. HO.

I.

II.

III.

1st Crystallization. 2nd Crystallization. New portion.

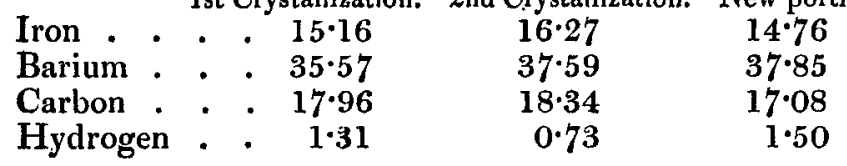

But a new portion of barytes salt did not give the same result; the portion analysed was in prismatic crystals, and crystallized twice.

I. 11.65 grs. gave 6.58 grs. $\mathrm{BaO}, \mathrm{SO}^{3}$ and $2 \cdot 49$ grs. $\mathrm{Fe}^{2} \mathrm{O}^{3}$. II. 17.22 grs. gave 9.83 grs. $\mathrm{BaO}, \mathrm{SO}^{3}$ and 3.58 grs. $\mathrm{Fe}^{2} \mathrm{O}^{3}$.

I. 6.87 grs. gave 3.87 grs. $\mathrm{CO}^{2}$ and $0.52 \mathrm{gr}$. HO. II. 13.62 grs. gave $7 \cdot 44$ grs. $\mathrm{CO}^{2}$ and 0.69 gr. $\mathrm{HO}$.

* The barytes used in decomposing the nitroprusside of copper was that made by boiling peroxide of manganese with sulphuret of barium. It always contains a little hyposulphite, and the brown precipitate was found to contain sulphate of barytes. 


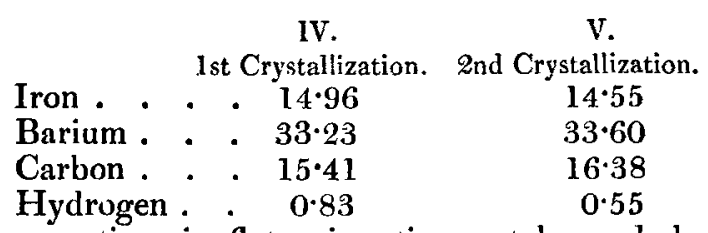

Another portion, in flat prismatic crystals, made by neutralizing nitroprussic acid with carbonate of barytes, gave the following results :-

12.33 grs. gave 6.61 grs. sulphate of barytes and $2 \cdot 42$ grs. peroxide of iron.

6.60 grs. gave 4.005 grs. carbonic acid and 1.040 gr. water.

VI.

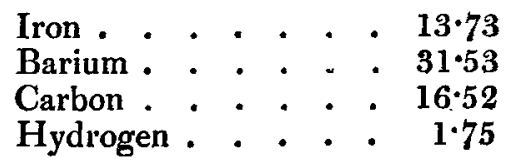

In this case the salt lost no more in the water-bath, although this was to have been expected from its larger quantity of hydrogen.

In all these cases the specimens were excellently crystallized, and yet there is a greater or less quantity of a foreign substance prevailing in all, and producing results so very discordant. In the first two portions analysed the barium is to the carbon $(37 \cdot 01: 17 \cdot 79)$ almost exactly as 1 equiv. : $5 \frac{1}{2}$ equivs., and the iron is to the carbon, sensibly though not so exactly, in the same proportion. In analysis VI., the iron is to the carbon as $28: 33 \cdot 7$, or rather more than $1: 5 \frac{1}{2}$, while the barium is to the carbon as $1: 6$. Again, in analyses IV. and V., the iron is to the carbon as $1: 5$, and the barium to the same element $1: 5 \frac{1}{2}$.

Finally, it will be seen further on that the silver salt made from these altered salts of barium do not contain this excess of carbon. The filtrate from the silver salts yields on evaporation and incineration a small quantity of a black ash, but the quantity being so small the nature of the substance could not be ascertained. We can scarcely suppose that it is a ferrocyanide, because we should have expected to have it precipitated by nitrate of silver, even though it could not be recognized by its usual tests. It would be useless without further information to speculate upon the probable nature of the impurity. Sufficient however has been shown to prove that the most complicated results may attend the analysis of specimens of nitroprusside of barium prepared from solutions which have been heated and thus partially decomposed. 


\section{Altered Nitroprusside of Sodium.}

23. The previous analyses of the crystallized nitroprussic acid and of the nitroprussides of ammonium and barium, and the composition of the silver salts prepared from them, show a want of accordance between the iron in the electro-negative constituent and the metal in the electro-positive one. The iron in all these cases is about a half per cent. in excess, therefore not sufficient to be considered as being in atomic proportion. It was thought, from the very distinct crystallization of the sodium salt, that this excess might not accompany it if prepared from the respective silver salts of the above compounds. Accordingly the silver salt was decomposed by an equivalent quantity of hydrochloric acid. The resulting solution was neutralized with carbonate of soda and crystallized. Analyses I. and II. were made on a salt thus prepared from crystallized nitroprusside of barium. Analysis III. on a salt similarly made from nitroprusside of ammonium. Again, when we referred to the action of caustic soda on the nitroprussides, it was obvious that by using a less quantity of the alkali than sufficed to effect the complete decomposition, a nitroprusside with a similar impurity in solution was to be expected.

Analysis IV. was made on a specimen thus prepared, and its accuracy is confirmed by a future analysis of a silver salt.

\{ I. 13.695 grs. gave 3.72 grs. peroxide of iron.

$\left\{\right.$ II. 20.93 grs. gave $5 \cdot 72 \mathrm{Fe}^{2} \mathrm{O}^{3}$ and $9.93 \mathrm{NaO}, \mathrm{SO}^{3}$. III. $15 \cdot 35$ grs. gave $4.25 \mathrm{Fe}^{2} \mathrm{O}^{3}$ and $7 \cdot 10 \mathrm{NaO}, \mathrm{SO}^{3}$. IV. $11 \cdot 13$ grs. gave $3.07 \mathrm{Fe}^{2} \mathrm{O}^{3}$ and $5 \cdot 06 \mathrm{NaO}, \mathrm{SO}^{3}$.

The combustions were made with chromate of lead.

II. 13.34 grs. gave 9.74 grs. $\mathrm{CO}^{2}$ and $1.58 \mathrm{gr}$. HO.

III. 14.475 grs. gave 10.68 grs. $\mathrm{CO}^{2}$ and $1.67 \mathrm{gr}$. HO. IV. $6 \cdot 730$ grs. gave 5.33 grs. $\mathrm{CO}^{2}$ and $1.01 \mathrm{gr}$. $\mathrm{HO}$.

\begin{tabular}{|c|c|c|c|c|c|}
\hline \multirow{6}{*}{\multicolumn{2}{|c|}{$\begin{array}{l}\text { Iron } \\
\text { Sodium : } \\
\text { Carbon : } \\
\text { Hydrogen } \\
\text { Nitrogen . } \\
\text { Oxvgen }\end{array}$}} & \multicolumn{2}{|c|}{ From barium salt. } & \multirow{2}{*}{$\begin{array}{l}\text { From ammonium } \\
\text { salt. } \\
\text { III. } \\
19 \cdot 38\end{array}$} & \multirow{2}{*}{$\begin{array}{c}\text { By action of } \\
\text { caustic soda. } \\
\text { IV. } \\
19.30\end{array}$} \\
\hline & & $\begin{array}{l}\text { I. } \\
19 \cdot 00\end{array}$ & $\begin{array}{l}\text { II. } \\
19 \cdot 12\end{array}$ & & \\
\hline & & ... & 15.37 & $15 \cdot 00$ & $14 \cdot 72$ \\
\hline & & $\ldots$ & $19 \cdot 91$ & $20 \cdot 12$ & 21.59 \\
\hline & & ... & $1 \cdot 31$ & $1 \cdot 21$ & $1 \cdot 65$ \\
\hline & & $\cdots$ & $44 \cdot 39$ & $44 \cdot 29$ & $42 \cdot 74$ \\
\hline & & & $00 \cdot 00$ & 100.00 & 00 \\
\hline
\end{tabular}

It will be seen from these analyses that the excess of iron still remains, and this is further confirmed by silver salts again made from them and analysed. It will also be observed that 
in specimen IV, we have the same remarkable increase in carbon as observed in the barium salt; the sodium is to the carbon as $1: 5 \frac{1}{2}$, which is exactly the proportion found in the latter salt; but this excess of carbon does not go down with a silver salt made from it.

\section{Examination of the Silver Salts made from the altered Nitro- prussides.}

24. To save unnecessary repetition, the numerous analyses made of the silver salts are here brought together, although it might have been more distinct to have introduced them under the respective salts from which they were made. The reason for converting them into silver salis was, that from the high atomic weight of silver and its accuracy of determination, the atomic accordance or disagreement between it and the iron could more readily be perceived.

Analyses I. II. and III. were made on three different preparations of silver salt made from three different specimens of crystallized nitroprussic acid, by adding the latter to nitrate of silver.

Analysis IV. was made upon a portion of II. treated on sand-bath with strong nitric acid in the hope of dissolving out the excess of iron. A very small quantity of iron was detected in solution by prusside of potassium.

Analysis V. was made on the sitver salt prepared from crystallized nitroprusside of ammonium.

Analyses VI. and VII. from silver salt precipitated from crystallized nitroprusside of barium, which contained 17.96 grs. of carbon, or in which the barium was to the carbon as $1: 5 \frac{1}{2}$.

Analysis VIII. On previous silver salt digested on the sand-bath with strong nitric acid to dissolve out excess of iron.

Analysis IX. On silver salt made from the crystallized sodium salt (No. 2) containing 19.91 grs. carbon.

Analysis X. Silver salt prepared from sodium salt (No. 4) containing 21.59 carbon, or in which the sodium was to the carbon as $1: 5 \frac{1}{2}$. In order if possible to remove the excess of iron, the salt was first precipitated by sulphate of copper and washed, the copper salt was now decomposed by soda and crystallized, and the silver salt was precipitated from this newly-crystallized portion.

\footnotetext{
I. 19.605 grs. gave 3.77 grs. $\mathrm{Fe}^{2} \mathrm{O}^{3}$ and 12.86 grs. $\mathrm{Ag} \mathrm{Cl}$. II. 16.795 grs. gave $3.24 \mathrm{Fe}^{2} \mathrm{O}^{3}$ and $10.94 \mathrm{Ag} \mathrm{Cl}$.

III. $13.580 \mathrm{grs}$. gave $2.60 \mathrm{Fe}^{2} \mathrm{O}^{3}$ and $8.79 \mathrm{Ag} \mathrm{Cl}$. IV. 6.765 grs. gave $1.35 \mathrm{Fe}^{2} \mathrm{O}^{3}$ and $4.355 \mathrm{Ag} \mathrm{Cl}$.

Phil. Mag. S. 3. Vol. B6. No. 243. April 1850. 
V. $14 \cdot 68$ grs. gave $2 \cdot 80 \mathrm{Fe}^{2} \mathrm{O}^{3}$ and $9 \cdot 44$ grs. $\mathrm{Ag} \mathrm{Cl}$.

$\left\{\right.$ VI. $13 \cdot 16$ grs. gave $2 \cdot 43 \mathrm{Fe}^{2} \mathrm{O}^{3}$ and $8.535 \mathrm{Ag} \mathrm{Cl}$.

VII. $24 \cdot 4 \mathrm{l}$ grs. gave $4 \cdot 54 \cdot \mathrm{Fe}^{2} \mathrm{O}^{3}$ and $15 \cdot 79 \mathrm{Ag} \mathrm{Cl}$.

VIII. 15.21 grs. gave $2.88 \mathrm{Fe}^{2} \mathrm{O}^{3}$ and $9.89 \mathrm{Ag} \mathrm{Cl}$.

IX. 13.60 grs. gave $2 \cdot 60 \mathrm{Fe}^{2} \mathrm{O}^{3}$ and $8 \cdot 80 \mathrm{Ag} \mathrm{Cl}$.

X. 8.81 grs. gave $1.69 \mathrm{Fe}^{2} \mathrm{O}^{3}$ and $5.59 \mathrm{Ag} \mathrm{Cl}$.

The combustions were made partly with chromate of lead, partly with oxide of copper.

I. 12.05 grs. gave 6.08 grs. $\mathrm{CO}^{2}$ and $0.10 \mathrm{gr}$. HO.

II. 12.195 grs. gave $6 \cdot 10 \mathrm{CO}^{2}$ and $0.08 \mathrm{HO}$.

IV. $8 \cdot 10$ grs. gave $4.03 \mathrm{CO}^{2}$ and $0.09 \mathrm{HO}$.

V. 10.35 grs. gave $5.13 \mathrm{CO}^{2}$ and $0.21 \mathrm{HO}$.

VI. 14.52 grs. gave $7 \cdot 18 \mathrm{CO}^{2}$ and $0.05 \mathrm{HO}$.

VIII. 9.56 grs. gave $4.85 \mathrm{CO}^{2}$ and $0.04 \mathrm{HO}$.

IX. 10.835 grs. gave $5.50 \mathrm{CO}^{2}$ and $0 \cdot 10 \mathrm{HO}$.

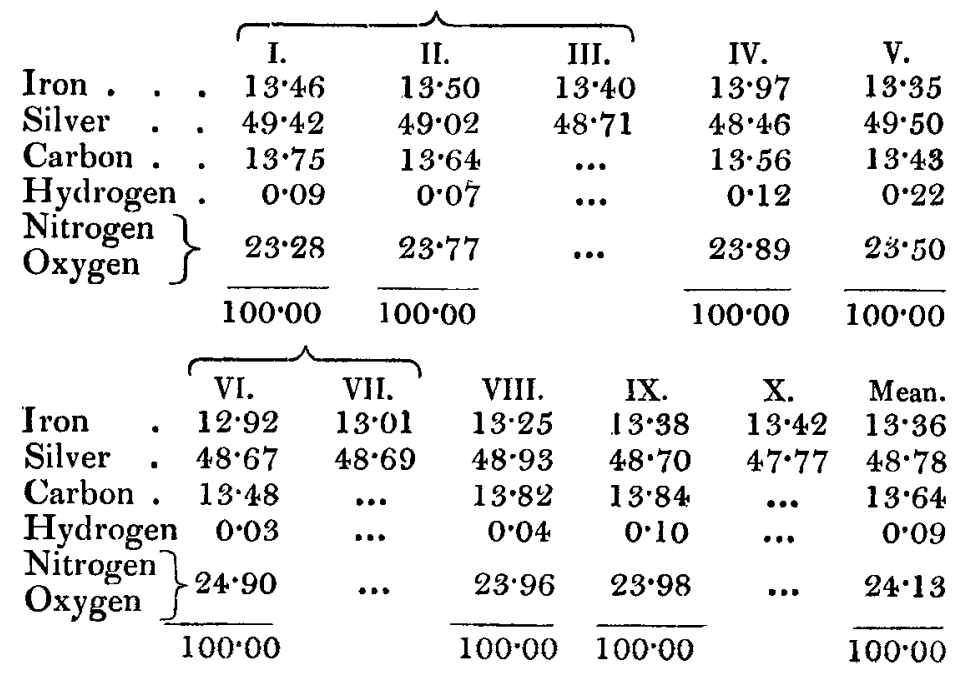

If we assume the mean iron, $13 \cdot 36$, to represent the true quantity, then the silver to correspond to it in atomic proportion should have been $51 \cdot 53$, whereas there is only $48 \cdot 78$. Hence there is 0.72 of iron in excess over the equivalent quantity; this excess corresponds to $\frac{1}{18}$ th of an equivalent. Again, supposing the carbon to be in the same proportion to the silver as in the nitroprussides, there should have been 13.0 , so that there is an excess of $0 \cdot 64$. The excess of iron and of carbon is therefore almost exactly as 1 equiv. : 4 equivs., or viewing the carbon as representing cyanogen as $1: 2$. On this view the amount of impurity in the silver salt is $2 \cdot 10$ per 
cent. Calculating the mean analysis deprived of this supposed impurity, we have

\begin{tabular}{|c|c|c|}
\hline \multirow{6}{*}{$\begin{array}{l}\text { Iron } \\
\text { Silver : } \\
\text { Carbon } \\
\text { Hydrogen } \\
\text { Nitrogen } \\
\text { Oxygen }\end{array}$} & & Theory of nitroprussi \\
\hline & . $12 \cdot 92$ & 13.01 \\
\hline & . 49.81 & $50 \cdot 18$ \\
\hline & - 13.28 & $13 \cdot 38$ \\
\hline & . $\quad 0.097$ & $0 \cdot 18$ \\
\hline & $23 \cdot 02$ & 23.25 \\
\hline & 100 & $100 \cdot 00$ \\
\hline
\end{tabular}

In the previous calculation the cyanide supposed to be present is $\mathrm{Fe} \mathrm{Cy}^{2}$; this only denotes the proportion of iron to the cyanogen; it is possible though less probable that it might be $2(\mathrm{Fe} \mathrm{Cy}+\mathrm{HCy})$. In this case we might suppose the anaJysed silver salts to contain this cyanide somewhat in the following proportion: 7 equivs. nitroprusside to 1 equiv. of the supposed cyanide. On this supposition the calculated and actual numbers would be as follows :-

\begin{tabular}{|c|c|c|}
\hline & Calculated. & Mean. \\
\hline Iro & . $13 \cdot 50$ & \\
\hline ver & $4 \cdot 9 \cdot 26$ & $48 \cdot 78$ \\
\hline Carbon . & . $\quad 13 \cdot 76$ & 13.64 \\
\hline drogen & . $\quad 0.20$ & 0.09 \\
\hline
\end{tabular}

It is not however to be supposed that this cyanide is present as a chemical compound in the above proportion, as the differences in the analyses show that it occurs in varying and not very definite proportions.

It would indeed appear that the barium and sodium nitroprusside contained a body in which the iron and cyanogen are in the same proportion as in ferrocyanogen $(\mathrm{Fe} \mathrm{Cy})$. But as the silver salt precipitated from them does not contain an excess of carbon, it can scarcely be supposed that this would not be precipitated. But in fact there are no data further than the mere ultimate analyses upon which reasoning can be founded with regard to this dissolved and combined foreign substance in the partially decomposed nitroprussides. As however all their essential characters and their crystalline form remain altogether unaltered, we cannot view the foreign substances as more than accidental.

[To be continued.] 